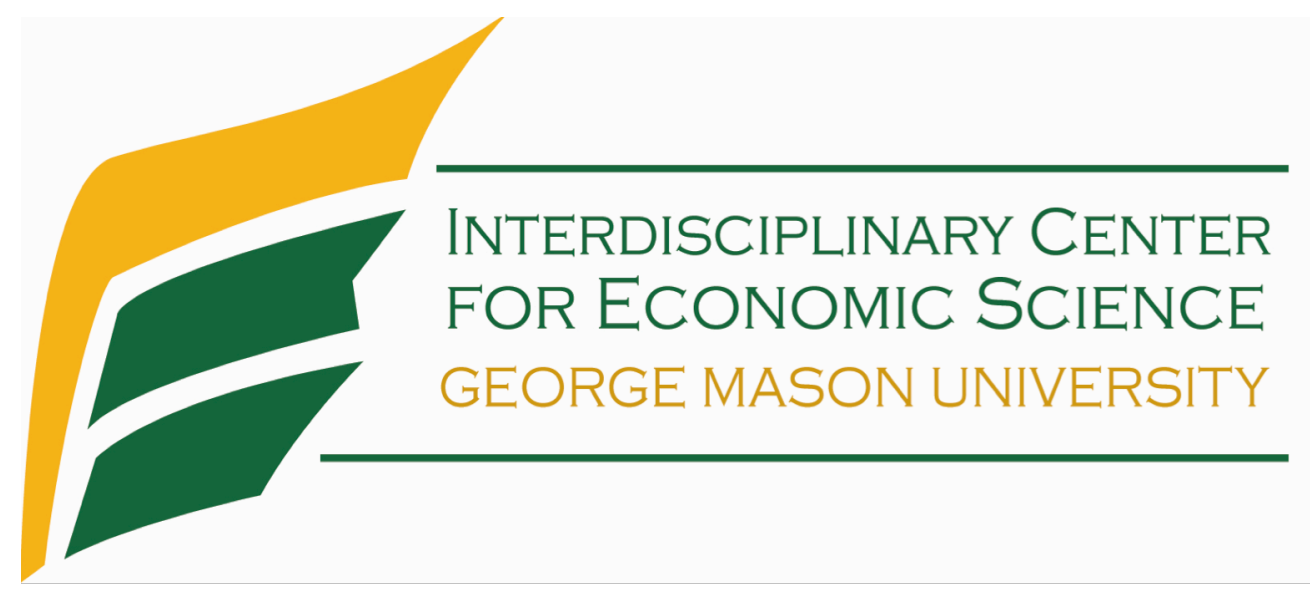

\title{
What if Wages Fell During a Recession?
}

\author{
Joy Buchanan and Daniel Houser
}

June 2017

Discussion Paper

Interdisciplinary Center for Economic Science

4400 University Drive, MSN 1B2, Fairfax, VA 22030

Tel: +1-703-993-4719 Fax: +1-703-993-4851

ICES Website: http://ices.gmu.edu

ICES RePEc Archive Online at: http://edirc.repec.org/data/icgmuus.html 


\title{
What if Wages Fell During a Recession?
}

\author{
Joy Buchanan and Daniel Houser*
}

June 2017 Working Paper

\begin{abstract}
Many economies exhibit downward wage rigidity. Surveys of managers by Bewley [1999] and Campbell and Kamlani [1997] indicate that employers hold wages rigid because they believe morale will suffer after a wage cut. Otherwise, there is little evidence for how employers' beliefs about workers contribute to wage rigidity and whether those beliefs are accurate. We demonstrate that effort falls after workers experience a wage cut and also that workers form reference points from wage contracts. Despite this partial confirmation of the "morale theory" as an explanation for wage rigidity, half of the employers in our experiment cut wages and lose money as a result. Because our design allows us to compare beliefs and effort precisely, we find that when employers don't believe the morale theory they will not hold wages rigid. In a treatment where a recession is offset by nominal inflation, real wage cuts do not have a significant effect. Loss averse employers are less likely to cut wages and more likely to correctly predict the negative effect of wage cuts. (JEL codes: C92, D84, J31)
\end{abstract}

\section{Introduction}

Why do we observe high unemployment during a recession instead of wage cuts? Nominal wage cuts were rare during the Great Recession in the US economy (e.g., Daly and Hobijn [2014]) and are uncommon in most countries (Dickens et al. [2007] provide an international comparison). ${ }^{1}$ There is extensive data on downwardly rigid wage contracts but very little evidence from the counterfactual: what happens if wages fall?

One cause of wage rigidity advanced by Akerlof et al. [1996] is that managers do not cut wages because they expect that wage cuts will lower worker morale and thereby reduce productivity. Bewley [1999] presented evidence supporting the morale theory from interviews with industry managers who said they believe that workers retaliate against wage cuts. The goal of this paper is to provide data at the individual level to test the morale theory of wage rigidity in an environment that eliminates the confounds of menu costs and peer comparison.

\footnotetext{
*Buchanan (corresponding author): Brock School of Business, Samford University, Birmingham, AL, USA; Houser: Department of Economics, George Mason University, Fairfax, VA, USA

${ }^{1}$ Daly and Hobijn [2014] use the Current Population Survey data to show that the number of wage freezes increased after the Great Recession. The distribution of wage changes implies that firms were avoiding wage cuts by keeping wages rigid. They are able to replicate this data pattern using a model in which some percent of workers cannot renegotiate their wage contract in a given period. Our research question is why it appears that many employment contracts cannot be renegotiated and what common characteristics rigid agents might share. Schmitt-Grohé and Uribe [2016] document that nominal wages are downwardly rigid in emerging countries. See Buchanan [2017] for a review of the literature.
} 
In a controlled experiment, we observe the wage level set by an employer, before and after a simulated recession, and the precise effort level chosen by workers in response to their wage. Additionally, employers make incentivized predictions that we are able to compare to the actual behavior of workers. In the Recession treatment, the available surplus shrinks such that an employer may feel justified in cutting wages to share the impact of the adverse event. In an additional treatment, the recession is offset by nominal inflation, so that we can compare the reaction to real versus nominal wage cuts. The outcome of many monetary policy measures depends on how nominal and real wage cuts are perceived by workers.

Our findings corroborate recent studies that show labor supply is affected by reference points. Gachter and Thoni [2010] and Bracha et al. [2015] provide experimental evidence that workers reduce effort if they learn that they are earning less than their peers. Workers in a field experiment by Kube et al. [2013] reduce the number of books they catalog for a library after their wage is cut relative to what was indicated in the job advertisement. In many of these studies, the wage is set by the experimenter. In our experiment, the wage is set by another participant and we provide no reference point aside from what they experience in past contracts with that counterpart. We find that workers react negatively to wage cuts. If employers reduce the wage, after a 3-round fixed-wage contract, the worker they are matched with reciprocates with a significant reduction of effort.

This paper presents a novel test of whether workers retaliate against wage cuts when the wage is endogenous and whether employers have correct beliefs about the effect of wage cuts. The experimental design is explained in the following section. In Section 3, we present a theory of wage-setting that incorporates beliefs employers hold about worker reciprocity. Results are presented in Section 4 and we conclude in Section 5.

\section{Experimental Design}

Our experiment was designed to allow precise measurement of individual effort. ${ }^{2}$ That measure can be compared with the beliefs employers report about how workers will behave after a wage change. Subjects play a modified gift exchange game (following the design of Fehr et al. [1993]) for 7 rounds with the same partner.

\subsection{Gift Exchange}

At the beginning of each round, the employer sets a nominal wage, $n \in[3, R]$, where $R$ is an exogenous constant. The real wage, $w$, is the nominal wage divided by the exchange rate, initially set at $130 \mathrm{ECUs} / \$$ (Experimental Currency Units). The worker's payment for a round is $w-c(e)$. They pay the explicit cost, $c(e)$, of the effort level they choose, $e \in\{0.05,0.1, \ldots, 1\}$. The cost of effort increases from one cent for the minimal effort level to $\$ 0.80 .^{3}$ A table of effort costs is in the instructions in Appendix C. In nominal terms, the employer earns $(R-n) * e$. The wage is presented to both employers and workers in nominal terms and the exchange rate is explained in the instructions. After the worker responds with an effort level choice, each round ends with a feedback stage where players learn their nominal profit and the employer learns the effort level chosen by the worker. We use the terms employer and firm interchangeably in this paper. The subjects only saw 'employer' and 'employee' to denote their roles throughout the experiment.

The first round is a paid practice round. Next, there is a 3-round fixed-wage contract. Workers can set a new effort level in each round but employers only select a wage in round 1,2 , and 5 . Between rounds 4 and 5 , subjects view information about experiment parameters which, in some treatments, is different from the original parameters.

Figure 1 shows a timeline of how parameters change in treatments Recession and Inflation. All treatments use identical instructions and are the same until the information stage after round 4.

\footnotetext{
${ }^{2}$ Specifically, we want to measure "unobservable" effort that relies on good morale. Our design differs from other experiments that pay a piece-rate wage for effort (i.e. Doerrenberg et al. [2016] conduct an on-line experiment and find an asymmetric response in labor supply to lowering the piece-rate wage).

${ }^{3}$ It is possible for workers to be constrained in their choice by a very low wage. Neither the employer nor the worker is allowed to lose money.
} 


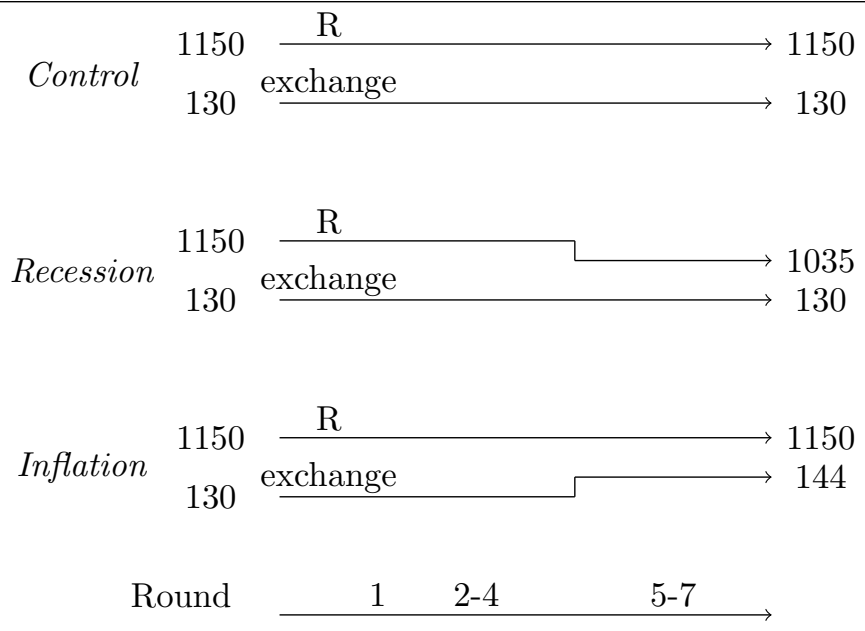

Figure 1: Timeline of Parameters in each Treatment

Figure 2 provides a screenshot of the announcement subjects see during the information stage of the Recession treatment.

In the Recession treatment, employers are confronted with a shrinking pie to share between themselves and the worker they are matched with. By the theory of inequality aversion, both the employer and the worker might decide that it is appropriate to share the impact of this adverse event. However, if workers anchor their expectations around their previous nominal wage contract, then workers may perceive a wage cut as unkind and reciprocate with an unkind reduction in effort.

Worker morale is an important issue to firms because workers cannot be monitored perfectly. In our experiment, a worker who had been cooperating can drop their effort level after round 4 without any fear of retribution. We allow for a fall in productivity to happen because that is what managers ostensibly want to avoid by keeping wages rigid. Campbell and Kamlani [1997] found in a survey of 184 firms that managers believe a $10 \%$ wage cut would lead to more than a $10 \%$ reduction in effort. We choose a recession size of $10 \%$ for our design to be comparable to this survey.

The parameters are such that, if an employer sets a wage in round 2 and keeps that wage "rigid" by setting the same wage in round 5, the employer would absorb all the loss in Recession. If the employer keeps wages nominally rigid in Inflation, the worker would experience a real wage cut because the price level increases. Introducing a one-time change in the price level has a large effect on the real trading price of assets in an experiment by Noussair et al. [2012] which they explain as sellers resisting nominal losses.

\subsection{Belief Elicitation}

In round 5, employers set the final wage level and the employee choses an effort level. Before the profits and effort level is reviewed, subjects read a new page of instructions for the belief elicitation. Subjects learn the following history about a worker who is in their session but who is not in their pair: wage and effort in round 4 , and wage in round 5 . Note that this is the first time in the experiment that subjects learn anything about a subject outside their own employer/worker pair.

After learning the history of another worker, subjects guess the effort level that this worker chose in round 5. If they guess correctly, they earn an additional $\$ 2$ at the end of the experiment. The purpose of this design is to better understand why firms choose wage offers and we expect that beliefs play an important role in that decision. 
Figure 2: Screenshot of New Information Stage

You have just completed round 4 of the experiment. There are 3 more rounds remaining. There is a change in the experiment for the following 3 rounds. The profit calculation for employers will be (1035-wage)*effort. The exchange rate remains $130 \mathrm{ECU}$ per dollar.

Click OK to continue

\subsection{Procedures and Subjects}

Subjects were recruited from the student population through an email recruitment system. The experiment was conducted at visually isolated computer terminals using ztree software Fischbacher [2007]. The instructions are in Appendix C. During the instruction phase, subjects had several practice tasks that they did on the computer. All subjects entered a wage and effort level and then calculated the profit for a hypothetical employer based on those choices. They had a calculator available for this stage. This familiarized them with the interface and ensured that they understood the employer profit function.

After the experiment, subjects completed a short questionnaire. In response to the survey about race, $33 \%$ selected white. The female percentage in each treatment ranged from $48 \%$ to $53 \%$. More than half of subjects reported having a part-time job.

For the loss aversion elicitation after the experiment, subjects made 6 yes-or-no choices. They could choose to participate in up to 6 lotteries that involve a risk of losing money. To determine which of the lotteries would be played, a volunteer rolled a 6 -sided die. The volunteer flipped a coin to determine the outcome of the lottery.

There were 288 subjects in the experiment; 96 subjects participated in each treatment and no subject participated in more than one treatment. Subjects were paid a $\$ 5$ show-up fee in addition to their lottery earnings (if any) and what they earned in the experiment (on average \$16). Every round was paid. The experiment lasted about an hour and 15 minutes including private payment.

\section{Model and Hypotheses}

There is no monetary incentive for workers to reciprocate above-minimum effort in exchange for high wages, especially in the endgame after the final wage has been set. However, we expect a positive correlation between wages and effort; this reciprocal behavior has been replicated many times (e.g., Brandts and Charness [2004]; Hannan et al. [2002]). Therefore, we model a worker with the following utility function that allows reciprocating high effort for high wages:

$$
U_{t}=w_{t}-c\left(e_{t}\right)+\frac{\alpha}{1+\lambda_{t}} * w_{t}^{\beta} * e_{t}
$$


,$\alpha \geq 0$ and $\beta>0$. The real wage in time $t$ is $w_{t}$ and $c\left(e_{t}\right)$ is the real cost of effort. The cost function has the usual form: $c(0)=0, c^{\prime}>0, c^{\prime \prime}>0$. The last term predicts that the second mover (worker) in the game helps the first mover (employer) if the worker feels that she has been treated well. Our concept of reciprocity follows Cox et al. [2007]. In our experiment, the cost function is specifically $c(e)=0.8 e^{1.5}$ which we will use for the example going forward.

The loss aversion parameter, $\lambda$, is forced to zero at the initial stage $t=0$ and also if the worker did not experience a wage cut. Using the nominal wage in the previous period, $n_{t-1}$, as a reference point, the loss aversion function is defined as

$$
\lambda_{t}=\left\{\begin{array}{ccc}
0 & \text { if } & n_{t} \geq n_{t-1} \text { ort } t=0 \\
\lambda & \text { if } & n_{t}<n_{t-1}
\end{array}\right\} .
$$

In the initial stage, without loss aversion and using our specific cost function, the workers best-response effort function is

$$
\hat{e}\left(w_{0}\right)=\frac{\alpha^{2}}{1.44} * w_{0}^{2 \beta}
$$

Thus, the elasticity of effort in response to wage is $2 \beta$. Paired with this worker, an employer maximizes profit by setting the wage according to

$$
w_{0}^{*}=\frac{\beta R_{0}}{\beta+\frac{1}{2}} .
$$

The profit-maximizing wage depends positively on $R$. Thus, if $R$ falls, which we will call a recession, $w^{*}$ also falls. Absent concerns about loss aversion, wages should fall in a recession.

If the interaction proceeds past the initial stage, then the choices in the initial stage could affect the way a worker evaluates if she has been treated well. ${ }^{4}$ If the subsequent wage, $w_{1}$, is less than the initial wage, $w_{0}$, then the worker might experience a sense of loss measured by $\lambda .^{5}$

The effort function accounting for loss aversion is

$$
\hat{e}\left(w_{t}\right)=\left(\frac{\alpha}{1.2\left(1+\lambda_{t}\right)}\right)^{2} * w_{t}^{2 \beta} .
$$

If $\lambda$ is larger than some threshold value $\underline{\lambda}$, it is not profitable to cut wages in a recession because effort would fall and total profit would be lower than if the wage stays fixed. The value of $\underline{\lambda}$ is derived in Appendix $\mathrm{B}$, along with the derivations of the optimal effort and wage functions. The optimal wage, allowing for loss aversion is

$$
w_{0}^{*}=\left\{\begin{array}{ccc}
n_{t-1} & \text { if } & \lambda_{t}>\underline{\lambda} \\
\frac{\beta R_{t}}{\beta+\frac{1}{2}} & \text { if } & \lambda_{t} \leq \underline{\lambda}
\end{array}\right\} .
$$

Figure 3 illustrates an example. Figure 3 plots the firm profit as a function of the nominal wage offer, assuming that the firm faces a worker who uses $\hat{e}(w)=\frac{0.3^{2}}{1.44} * w_{0}^{2 * 0.2}$ as an effort response function. The higher blue line shows this function at $R=1150$ and the profit maximizing wage is marked by the vertical line at 328. The parameters $\alpha=0.3$ and $\beta=0.2$ remain constant in the example.

If $R$ falls to 1035 , as it does in the experiment, then the optimal wage falls to 296 marked by the dot in figure 3. The height of the dot indicates the highest profit the firm could make after a fall in $R$ if the worker is not loss averse. The dashed line shows the profit to the firm if the wage is cut and the worker is loss averse, supposing $\lambda=1.1$. Effort falls by so much after a wage cut that the profit-maximizing strategy for this firm after the recession is to keep wages rigid.

\footnotetext{
${ }^{4}$ If we suppose, like Köszegi and Rabin [2006], that agents have a reference point based on (rational) expectations then this experiment is a novel contribution toward answering the question of how those expectations are formed. Do workers expect that their wages will stay the same, regardless of changing economic conditions?

${ }^{5}$ The resulting best-response effort function would be the same if $\lambda$ is inserted as follows: $U=w-c(e) *(1+\lambda)+\alpha * w^{\beta} * e$. In that presentation, experiencing a wage cut increases the cost of working.
} 


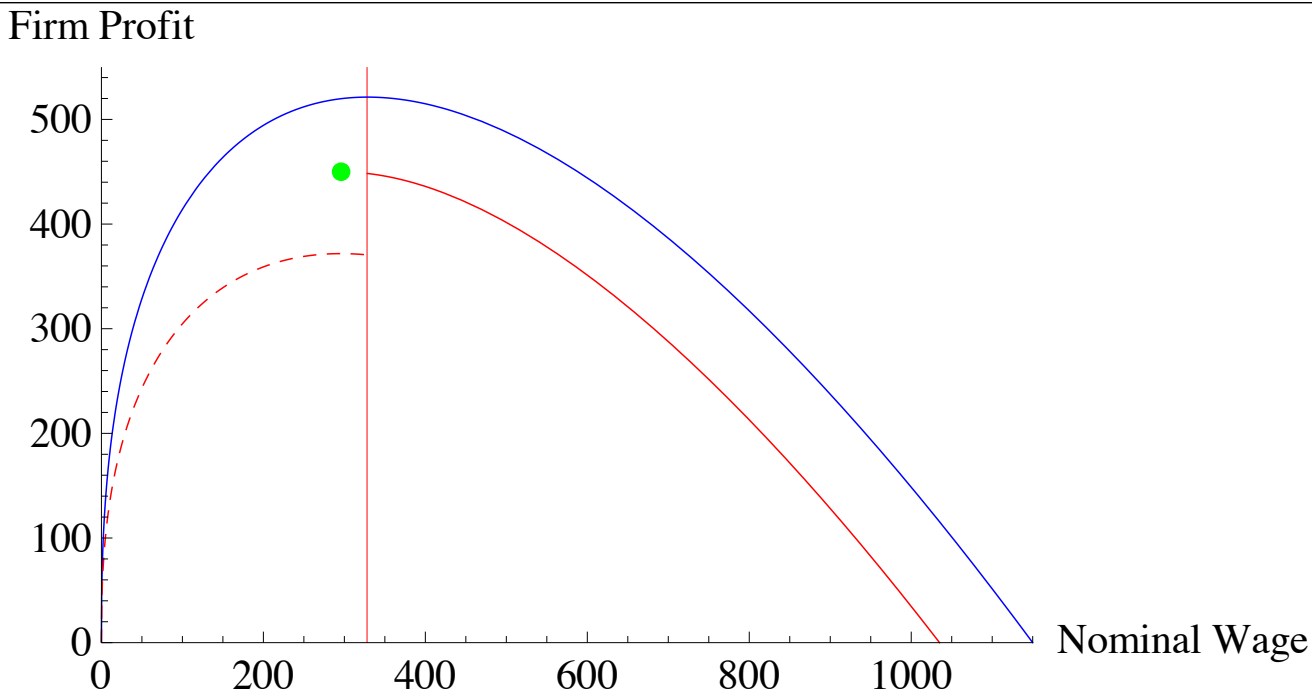

Figure 3: Firm Profit Before and After a Recession

Our experiment is designed to test the following main hypotheses:

Hypothesis 1: Workers will reduce effort if they experience a nominal wage cut. Specifically, they will give less effort per wage received, thus, $H_{A}: \lambda>0$.

Hypothesis 2: Anticipating hypothesis 1, employers will avoid nominal wage cuts.

Additionally, we can compare the effect of real wage cuts when they are masked by inflation. Whether workers are more sensitive to nominal or real wage cuts is an empirical question left open by Dickens et al. [2007] who found that nominal wages in the U.S. are rigid downward but that countries like the U.K. exhibit considerable real rigidity.

\section{Results}

In the following section we present substantial evidence that wage cuts cause workers to reduce effort, which lowers the profits of firms. The subsequent sections contain the results of the incentivized belief elicitation and loss aversion elicitation. Beliefs and loss aversion both partially explain the choice of the employer to cut wages.

\subsection{Main Results for Wages and Effort}

It is evident in figure 4 that positive reciprocity is operating in round 4 , before the information stage differentiates the treatments. Workers with higher wages work harder. The average effort between treatments is similar in round 4 . We do not find treatment differences with either t-tests or the Kruskal-Wallis test.

The effort of workers who received a real wage of $\$ 2-\$ 4$ is similar to that of workers who received $\$ 4-\$ 6$. It appears that many workers who received any wage higher than $\$ 2$ felt that their wage was fair or adequate and they reciprocated with an effort level near the middle of the feasible effort range. That wage contract forms a reference point for workers. Three workers who received a wage above $\$ 6$ are not pictured. The number of worker in each bin is indicated in the graph.

About half of the workers in Control and Recession treatments experience a nominal wage cut. The second row of CDFs in figure 5 show the change in the wage distribution between rounds 4 and 5 . The average real wage went down slightly in Control and Recession. Those wage cuts had a large effect on the 


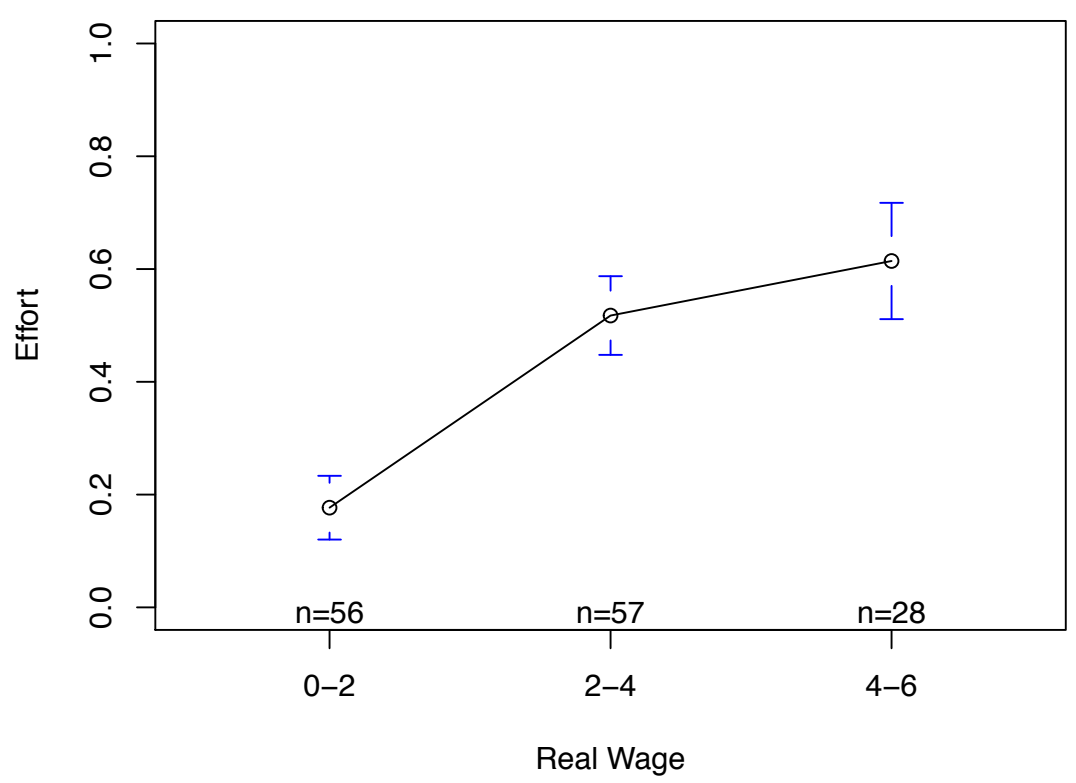

Figure 4: Effort in Round 4 by Real Wage

distribution of effort choices in round 5, shown in the first row of CDFs. Although half of the workers in Inflation receive real wage cuts, the distribution of effort does not noticeably change.

Figure 5 depicts the changes in the full sample between round 4 and 5 . The cumulative distribution of effort in Control and Recession drops significantly after half of the workers experience wage cuts. If we restrict the sample to workers who experienced a wage cut in round 5, then a Kolmogorov-Smirnov test confirms that effort fell in Control $(D=0.4, p-$ value $<0.09)$ and Recession $(D=0.37, p-$ value $<0.05)$.

Result 1: If a worker experiences a wage cut, they respond by reducing effort.

Because the effort choice is censored below at 0.05 , we use tobit analysis to measure the effect of a wage cut on effort between round 4 and 5 . We include a dummy for whether a worker experienced a real wage cut in each of our three treatments. We also include a dummy for round 5 to pick up a possible endgame effect that would cause effort for all the workers to fall.

Column (3) of table 1 shows tobit estimates for the following equation:

$e_{i t}=\beta_{0}+\beta_{1} \log (\text { RealWage })_{i t}+\beta_{2} I(\text { RealCut })_{i} \times I(\text { Control })_{i}+\beta_{3} I(\text { RealCut })_{i} \times I(\text { Recession })_{i}+$ $\beta_{4} I(\text { RealCut })_{i} \times I(\text { Inflation })_{i}+\beta_{5} I(\text { Round })_{t}+\epsilon_{i t}$

More than $20 \%$ of the workers pick an effort level of 0.05 in round 4 . In our preferred sample for analysis in table 1, we exclude some of those workers because they did not start with good morale and if they are upset by a wage cut they cannot go down any further. The preferred sample is the subjects who had, at least once in rounds 2-4, given an effort above 0.05. Pairs of subjects in which the worker chose an effort level above the minimum at least once in rounds $2-4$ are referred to as cooperating pairs, hereafter. See tobit estimates for the full sample in table A1.

The coefficient on Round 5 is nearly zero. There is no decline of effort in the endgame. Many workers are willing to reciprocate with an effort level above the minimum if they feel they are being treated well. Judging by the magnitude of the coefficients on the cut dummies, real wage cuts matter more in Control 

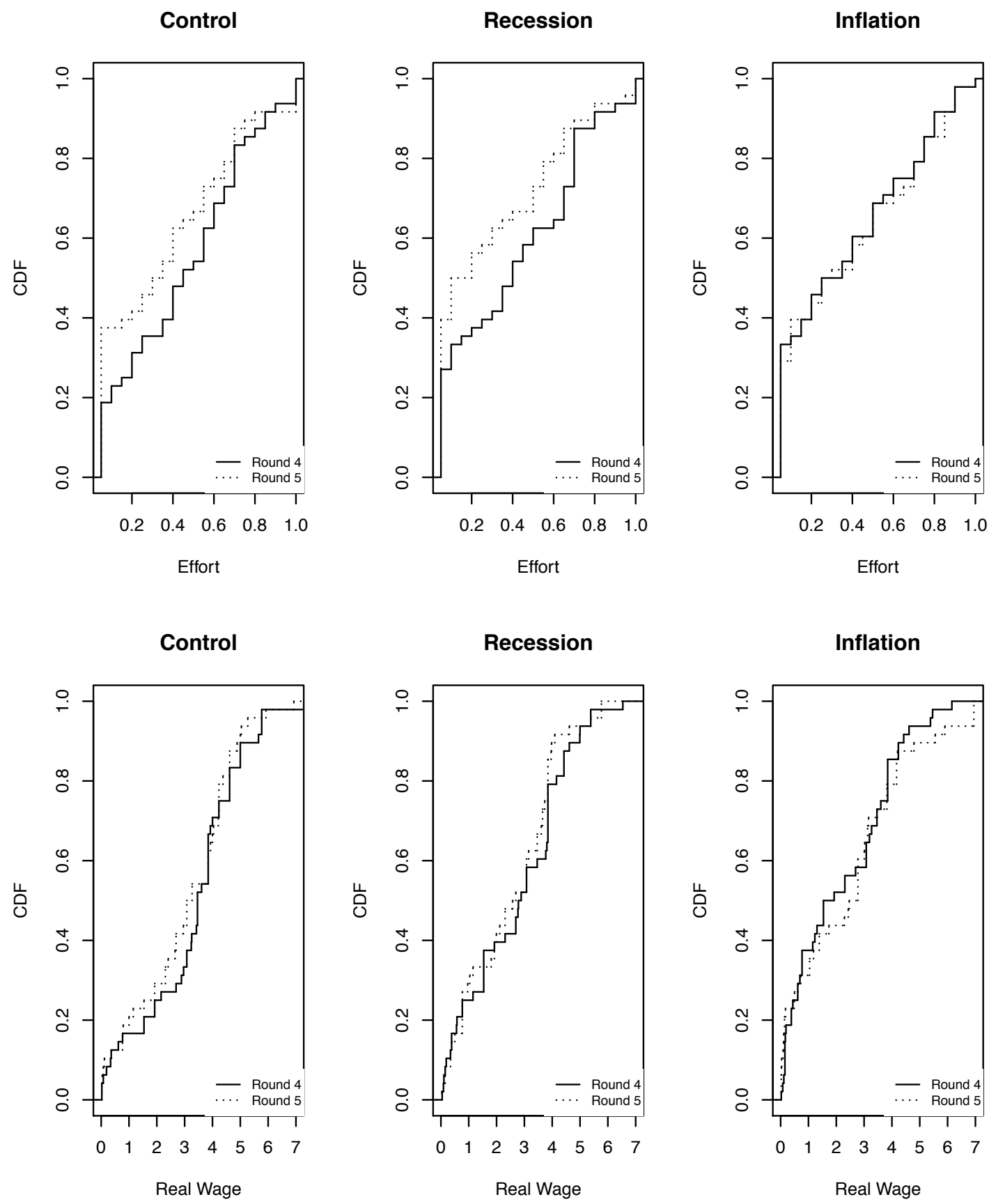

Figure 5: Cumulative Distribution of Effort and Real Wage in Rounds 4-5 by Treatment 
Table 1: Effort of Workers Round 4-5

\begin{tabular}{|c|c|c|c|}
\hline & $(1)$ & Tobit: effort & $(3)$ \\
\hline Real Wage & & $\begin{array}{c}0.108^{* * *} \\
(0.019)\end{array}$ & \\
\hline Log(Real Wage) & & & $\begin{array}{c}0.184^{* * *} \\
(0.037)\end{array}$ \\
\hline Real Cut, Control & $\begin{array}{c}-0.310^{* * *} \\
(0.103)\end{array}$ & $\begin{array}{c}-0.129^{*} \\
(0.074)\end{array}$ & $\begin{array}{c}-0.193^{* * *} \\
(0.072)\end{array}$ \\
\hline R. Cut, Recession & $\begin{array}{c}-0.298^{* * *} \\
(0.091)\end{array}$ & $\begin{array}{c}-0.182^{* * *} \\
(0.069)\end{array}$ & $\begin{array}{c}-0.216^{* * *} \\
(0.069)\end{array}$ \\
\hline R. Cut, Inflation & $\begin{array}{l}-0.079 \\
(0.099)\end{array}$ & $\begin{array}{l}-0.059 \\
(0.070)\end{array}$ & $\begin{array}{l}-0.112 \\
(0.068)\end{array}$ \\
\hline Round 5 & $\begin{array}{c}0.001 \\
(0.057)\end{array}$ & $\begin{array}{l}-0.023 \\
(0.032)\end{array}$ & $\begin{array}{l}-0.014 \\
(0.033)\end{array}$ \\
\hline Constant & $\begin{array}{c}0.485^{* * *} \\
(0.033)\end{array}$ & $\begin{array}{l}-0.018 \\
(0.123)\end{array}$ & $\begin{array}{c}0.153 \\
(0.112)\end{array}$ \\
\hline Subject F.E. & No & Yes & Yes \\
\hline Observations & 234 & 234 & 234 \\
\hline Log Likelihood & -125 & 70 & 67 \\
\hline
\end{tabular}

Notes: The table reports results of a tobit regression. Workers who did not give an effort above 0.05 in rounds 2-4 are excluded. The real wage cut dummy variables are equal to 1 if the worker experience a wage cut after round 4 , and 0 otherwise. Standard errors are in parentheses. ${ }^{*} \mathrm{p}<0.1 ;{ }^{* *} \mathrm{p}<0.05 ;{ }^{* * *} \mathrm{p}<0.01$ 


\section{RESULTS}

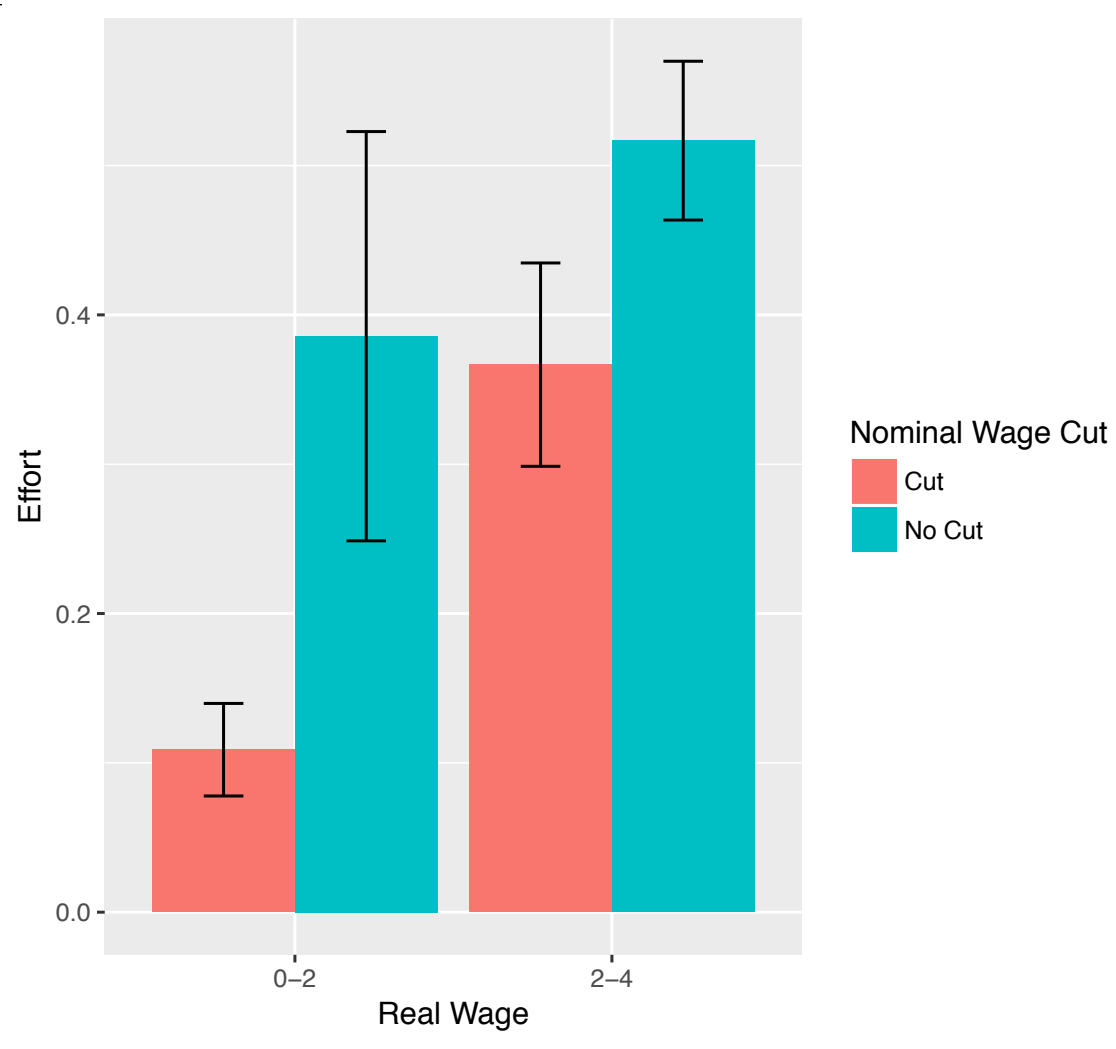

Figure 6: Comparing Effort after a Nominal Wage Cut, Columns show mean +/- S.E.M.

and Recession than in Inflation. The direction of the effect is negative for Inflation, but there is more noise, possibly due to nominal illusion.

Because wages cuts seem to be operating in a similar way in Control and Recession we pool them in Figure 6 and exclude Inflation. Further, we restrict the sample to workers who could possibly reduce effort if they wanted to, meaning that we only include workers who had chosen an effort level above 0.05 in round 4 .

Figure 6 shows the effort choices by workers in round 5 . Among workers who received a real wage between $\$ 0$ and $\$ 2$, there is a stark difference between the actions of the workers who had experienced a low wage already in round 4 and the workers who received a wage cut in round 5. The average effort level is nearly the midpoint of the effort range for workers who were not unpleasantly surprised by receiving a low wage.

The second pair of bars indicates the effort level of workers who received a real wage between $\$ 2$ and $\$ 4$. This illustrates the difference between workers who expected a wage of about $\$ 3$ and workers for whom that same wage is a violation of their expectations. The difference is not as large as what we observe in the lowest wage bin, however the effort of workers experiencing a cut is significantly lower than workers at the same wage level who did not receive a cut. This confirms the evidence we present in table 1 . The wage in round 4 became a reference point and workers retaliated against wage cuts.

The data in Figure 6 omits workers who received a real wage above $\$ 4$. Effort in the omitted wage category of 4-6 does not show a significant difference between cut and no cut; however the standard errors are large because the number of worker in that category is quite small. There are no Cut observations in the wage category above $\$ 6$.

Workers form a reference point after they are exposed to a fixed wage three times, from round 2 to round 4. We show that even after a recession workers do not expect that the contract will be renegotiated. See Fehr et al. [2011] for an experimental test of how reference points are formed through contracting. In that 
study, buyers and sellers (sellers are our "employees") are randomly re-matched every round.

Result 2a: Despite the decline in effort in response to wage cuts, wage cuts are common.

Table 2: Wage Cuts among Cooperating Pairs

\begin{tabular}{rccc}
\hline & Control & Recession & Inflation \\
\hline Average Magnitude of Nominal Wage Cuts & -169 & -154 & -210 \\
\hline Number (\%) of Nominal Wage Cuts & $18(43 \%)$ & $23(58 \%)$ & $12(34 \%)$ \\
\hline Average Magnitude of Real Wage Cuts & -1.3 & -1.18 & -1.35 \\
\hline Number (\%) of Real Wage Cuts & $18(43 \%)$ & $23(58 \%)$ & $17(49 \%)$ \\
\hline Number of Workers & 42 & 40 & 35 \\
\hline
\end{tabular}

Table 2 shows that nearly half of employers cut real wages between round 4 and round 5 (see table A2 for full sample). Nominal wage cuts occur nearly twice as often in Recession as in Inflation, which yields about the same number of real wage cuts in both treatments. The high frequency of nominal wage cuts is surprising, especially in Control.

Result 2b: Employers who cut nominal wages earn less in round 5.

Because effort went down in response to wage cuts, the profits earned in round 5 by employers who cut nominal wages was lower than profits earned by employers who did not cut wages (see t-test in table A3). Among cooperating pairs, employers who cut wages earned 63 cents less $(p-v a l .=0.03)$ or, on average, they would have earned $29 \%$ more had they not cut wages. In a regression controlling for treatment, a nominal wage cut has a significant negative effect on profits (see table A4).

\subsection{Estimating Model Parameters for Effort and Beliefs}

After the wage and effort decisions are made in round 5 (and before employers learn the effort choice of the worker they are paired with), participants are asked to predict the effort choice of another participant who is in the room but with whom they have not interacted. They learn the wage and effort response in round 4 and the wage offer in round 5 for that worker. If they can correctly guess the workers effort level in round 5 , they earn a bonus payment, so there is an incentive to be accurate.

Result 3: Employers do not anticipate how much effort falls after a nominal wage cut.

A nominal wage cut significantly reduces effort, as shown in the previous section. When predicting the actions of a worker in their experiment session, employers do not appear to understand the effect of wage cuts.

To compare the predicted and actual effect of nominal wage cuts, we estimate the parameter values of the model introduced in Section 3. Recall that $\alpha$ and $\beta$ measure positive reciprocity that leads to higher effort in response to higher wages. If workers react negatively to nominal wage cuts in a way that results in a discontinuity of the positive reciprocity function, then they have a positive value of $\lambda$.

The estimates presented in the first column of Table 3 are for the effort decisions in the actual data from

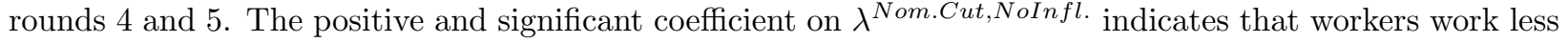
hard after receiving a nominal wage cut, when they are not distracted by inflation. Effort is more than $15 \%$ lower on average after a wage cut.

We obtain the coefficients with a nonlinear least squares estimation of the following equation:

$$
e_{i t}=\left(\frac{\alpha^{\text {Round4 }} I(\text { Round } 4)_{t}+\alpha^{\text {Round5 } I(\text { Round } 5)_{t}}}{1.2\left[1+\lambda^{\text {NoInfl }} \cdot I(\text { Nom.Cut })_{i} \times I(\text { Cont } .)_{i} \times I(\text { Rec } .)_{i}+\lambda^{\text {NoInfl }} \cdot I(\text { Nom.Cut })_{i} \times I(\text { Infl. })_{i}\right]}\right)^{2} * w_{i t}^{2 \beta}
$$


Table 3: Actual and Predicted Parameters of the Effort Function

Actual Effort, Rounds 4-5 Predictions by Employers for Effort in Round 5 and Actual Effort in Round 4

\begin{tabular}{lcc}
\hline$\beta$ & $0.177^{* * *}$ & $0.221^{* * *}$ \\
& $(0.034)$ & $(0.035)$ \\
$\alpha^{\text {Round } 4}$ & $0.728^{* * *}$ & $0.673^{* * *}$ \\
& $(0.035)$ & $(0.033)$ \\
$\alpha^{\text {Round } 5}$ & $0.728^{* * *}$ & $0.667^{* * *}$ \\
& $(0.039)$ & $(0.037)$ \\
$\lambda^{\text {Nom.Cut,NoInfl. }}$ & $0.193^{* *}$ & 0.087 \\
& $(0.082)$ & $(0.063)$ \\
$\lambda^{\text {Nom.Cut,Infl. }}$ & & \\
& 0.206 & -0.035 \\
& $(0.148)$ & $(0.078)$
\end{tabular}

\begin{tabular}{lll}
\hline Observations & 212 & 212 \\
\hline \hline
\end{tabular}

Notes: The table reports results of a nonlinear regression. Workers who provided effort of 0.05 in round 4 are excluded. The nominal wage cut dummy variables are equal to 1 if the worker experience a wage cut after round 4 , and 0 otherwise. Standard errors are in parentheses. ${ }^{*} \mathrm{p}<0.1$; ${ }^{* *} \mathrm{p}<0.05 ;{ }^{* * *} \mathrm{p}<0.01$

We estimate separate coefficients for round 4 and round 5 so that we are able to capture an endgame effect. Treatment names are abbreviated.

To compare beliefs with actual effort decisions, we merge the effort choices from round 4 with the predictions made by employers. The estimate for the predicted $\lambda^{\text {Nom.Cut,NoInfl. }}$ in the second column of Table 3 is less than half as large as the estimate for actual effort choices. Employers do not seem to realize how much wages cuts will upset workers. The sample in Table 3 excludes 38 workers who chose effort of 0.05 in round 4. Results for the full sample are reported in table A5.

Using the model described in Section 3 and the parameters used in the experiment, we can calculate a threshold level of $\lambda$ above which wage rigidity is a more profitable strategy for firms during a recession. The value 0.193 estimated for the actual effort decisions without inflation is well above that threshold level (see Appendix B for derivation). For most employers, keeping wages rigid would have been a more profitable strategy in this experiment.

Do workers also fail to predict what other workers will do? No. The predictions of workers merged with actions in round 4 yield a result closer to the actual effort estimate. As predicted by workers, the estimate for $\lambda^{\text {Nom.Cut,NoInfl. }}$ is 0.125 (s.e. 0.062 , p-val $=0.04$ ). The workers are in the same frame of mind as other workers, and the employers, perhaps, are not.

Note that subjects enter the lab together and complete identical instructions before being informed of their randomly assigned role in the experiment. Experience as an employer for 5 rounds seemingly changes the frame of mind of employers. To say the least, employers have a poor understanding of the reciprocity dynamics as indicated not just by their wage choice but by their predictions of worker behavior.

It is a question for future research whether employers would learn and adapt to the frame of mind of workers. Also, different environments could put workers out of the "system 1" (the unreflective reaction mode of action described by Kahneman [2011]) and cause them to behave more like the employers predicted they would. 


\subsection{Loss Aversion}

After our experiment, subjects answer several questions. We elicit loss aversion using a menu of 6 lottery choices. Every lottery offers a $50 \%$ chance to win $\$ 7$. The equally probably loss is $\$ 3$ in the first lottery and increases by $\$ 1$ for each subsequent lottery. A highly loss averse subject might decline a chance to play any of these lotteries. Our measure of loss tolerance is the total number of lotteries chosen by the individual. After every subject submitted their choices, one subject volunteered to roll a die and flip a coin. The die determined the lottery that would be paid and the coin flip determined whether the subjects who agreed to play that lottery would win $\$ 7$ or lose money out of their earnings in the experiment. Women exhibit considerably more loss aversion than men; however, gender does not appear to influence wage or effort choices.

Result 4: More loss averse employers are less likely to cut nominal wages, and they correctly anticipate the retaliation of workers against wage cuts.

Table 4: Effect of Loss Aversion on Likelihood of Cutting Nominal Wages

\begin{tabular}{lcc}
\hline \hline & \multicolumn{2}{c}{ Logit: Nominal Wage Cut Probability } \\
& $(1)$ & $(2)$ \\
\hline Loss Tolerance & $0.315^{* *}$ & $0.340^{* *}$ \\
& $(0.140)$ & $(0.145)$ \\
Recession & 0.703 & 0.680 \\
& $(0.486)$ & $(0.488)$ \\
Inflation & -0.225 & -0.277 \\
& $(0.504)$ & $(0.510)$ \\
Male & & -0.303 \\
& & $(0.428)$ \\
Constant & $-1.027^{* *}$ & $-0.922^{* *}$ \\
& $(0.446)$ & $(0.467)$ \\
\hline Observations & 106 & 106 \\
Log Likelihood & -68.737 & -68.484 \\
\hline \hline Note: & \multicolumn{2}{c}{${ }^{*} \mathrm{p}<0.1 ;{ }^{* *} \mathrm{p}<0.05 ;{ }^{* * *} \mathrm{p}<0.01$}
\end{tabular}

Table 4 indicates that, regardless of whether we control for gender, loss tolerant employers are more likely to cut nominal wages between round 4 and round 5 . The sample in table 4 excludes employers who were paired with a worker who chose the minimum effort level in round 4 because a worker at the minimum level cannot reduce effort any further (see table A6 for full sample). If we run an OLS regression for Model 1, then the coefficient on Loss Tolerance is positive $(0.072)$ and significant $(p<0.05)$. The probability of a wage cut increases if the subject accepts more lotteries in the decision task.

This effect is driven by the behavior of employers we call "loss averse". A loss averse subject rejected all of the lotteries or all except the first lottery which involved only a possible loss of $\$ 3$ and had the highest expected value. About one third of our total sample is loss averse, by this definition. Figure 7, using the same sample as table 4, shows the number of employers who cut nominal wages among employers who are loss averse and among all other employers who we call "loss tolerant". Among loss averse employers, less than one third of them cut nominal wages. Table A8 displays the data for the full sample. 


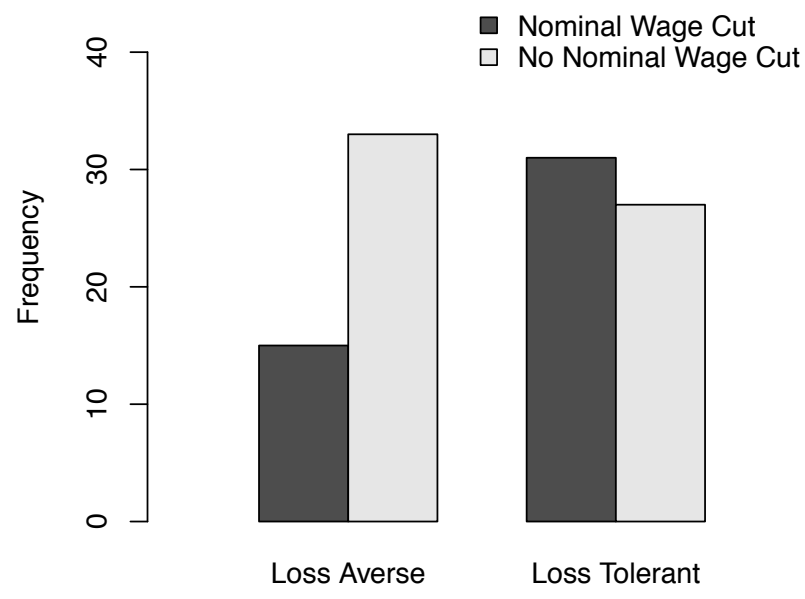

Figure 7: Instances of Nominal Wage Cuts by Loss Averse Employers

The different behavior of loss averse employers suggests that they might hold different beliefs about how workers react to wage cuts. Because our design allows us to measure beliefs, we can test that explanation. In table 5, we estimate the same model used in the second column of table 3. As before, we exclude firms paired with workers who gave an effort of 0.05 in round 4 and provide the full sample in table A7. When only using the predictions from loss averse employers, the coefficient on $\lambda^{\text {Nom.Cut,NoInfl. }}$ is large and marginally significant. The small coefficient in the second column suggests that employers who are loss tolerant do not expect wage cuts to impact effort. ${ }^{6}$

Abeler et al. [2011] found that loss aversion, as measured by similar lottery choices, predicted a subject's decision to stop working early at tedious tasks to avoid a loss. ${ }^{7}$ Using our data, we cannot effectively test whether effort provision is a function of loss aversion. Over $75 \%$ of workers among Cooperating Pairs cut effort if they received a wage cut, so we lack sufficient variation to adequately compare the highly loss averse from the less loss averse workers. Only 3 loss averse workers did not reduce effort in response to a nominal wage cut.

Reference-dependent taxi drivers in New York stop working once they have achieved a daily income target Crawford and Meng [2011], and similarly Abeler et al. [2011] show that experimental subjects will stop working early at a real effort task in order avoid a loss relative to an induced reference point. Subjects in the Abeler et al. study have a $50 \%$ chance of winning a fixed payment $f$ and often complete just enough tasks so that $50 \%$ of the time they would also obtain $f$ from their piece-rate earnings. Subjects considered loss averse (because they decline lotteries with a positive expected value to avoid possible losses) are more likely to stop working at the point that minimizes the potential for disappointment. Using a similar lottery menu to measure loss aversion, we find that loss averse employers are less likely to cut wages and they correctly believe that wage cuts will cause effort to fall. The loss tolerant employers earn less money; more than half of them cut wages and they do not seem to believe that wage cuts cause effort to fall.

\footnotetext{
${ }^{6}$ The same result is obtained by dividing workers into loss tolerant and loss averse groups. Loss tolerant workers do not predict that effort will fall in reaction to a wage cut. For loss averse workers, $\lambda^{\text {Nom }}$. Cut, NoInfl. $=0.16(\mathrm{~S} . \mathrm{E} .=0.08 ;$ p-value $=0.04)$.

${ }^{7}$ In a field experiment, Fehr and Goette [2007] also find that loss aversion correlates with the decision of bicycle messengers to stop working early to avoid loss.
} 
Table 5: Beliefs of Loss Averse and Loss Tolerant Employers

\begin{tabular}{lcc}
\hline & Predictions by Loss Averse Firms & Predictions by Loss Tolerant Firms \\
\hline$\beta$ & $0.224^{* * *}$ & $0.190^{* * *}$ \\
& $(0.061)$ & $(0.035)$ \\
& & \\
$\alpha^{\text {Round } 4}$ & $0.677^{* * *}$ & $0.722^{* * *}$ \\
& $(0.059)$ & $(0.036)$ \\
$\alpha^{\text {Round } 5}$ & $0.705^{* * *}$ & $0.668^{* * *}$ \\
& $(0.066)$ & $(0.039)$ \\
$\lambda^{\text {Nom.Cut }, \text { NoInfl. }}$ & $0.269^{*}$ & 0.013 \\
& $(0.161)$ & $(0.061)$ \\
$\lambda^{\text {Nom.Cut,Infl. }}$ & -0.045 & -0.012 \\
& $(0.106)$ & $(0.127)$ \\
\hline Observations & 82 & 130 \\
\hline \hline
\end{tabular}

Notes: The table reports results of a nonlinear regression. The nominal wage cut dummy variables are equal to 1 if the worker experience a wage cut after round 4 , and 0 otherwise. Standard errors are in parentheses. ${ }^{*} \mathrm{p}<0.1 ;{ }^{* *} \mathrm{p}<0.05 ;{ }^{* * *} \mathrm{p}<0.01$

\section{Conclusion}

Since wage cuts are rare in the economy and the output of individual workers is often unobservable, our experiment provides a unique opportunity to test the morale theory of wage rigidity. We find that workers cut effort significantly in reaction to nominal wage cuts. Although this fall in morale is often used as an explanation for wage rigidity, half of the firms cut wages. Nominal wage cuts are common in the experiment, and we do not observe more real wage cuts when employers could hide real wage cuts behind nominal inflation. The reason, as least in part, is that firms have incorrect beliefs about how workers will react to wage cuts.

Our experiment highlights the role of the beliefs in economy-wide wage rigidity. We have not ruled out other reasons for wage rigidity, such as menu costs and peer comparison. However, we have shown that a manager with correct beliefs will tend to avoid cutting wages, even in the absence of those forces, and in our environment they earn more money as a result.

We present a novel result that an inexperienced employer who avoids cutting wages is generally more loss averse. There is a growing literature indicating that labor supply is affected by loss aversion. Workers in our experiment are reacting to a loss instead of avoiding a loss. Interestingly, the workers who are more loss averse in our experiment are more likely to predict that other workers will react negatively to wage cuts. To our knowledge, we are the first to provide evidence that people who are more loss averse are more inclined to expect loss aversion in others. Our results lead to questions for future research. Do the same people who would pay to avoid a loss react the most strongly to losses they cannot avoid?

Economists cannot precisely define the circumstances under which workers perceive nominal wage cuts as offensive. Bracha et al. [2015] found that effort provision is affected by jealousy of a peer earning a higher wage. However, if a sufficient justification is given for unequal pay, the difference in effort provision disappears. Friedman [1968] argued that the effects of inflation diminish as people realized through experience what the real variables are. Negative reciprocity is contingent on the larger context of a decision Cox and Deck [2005]. It remains to be seen which contexts might induce workers to act in a way that is more in 


\section{REFERENCES}

line with the predictions of our naïve employers or might prompt employers to accurately perceive the insult caused by a wage cut (see Kendall and Oprea [2016] on belief correction).

Taylor [1980] proposed that price rigidity is partly due to staggered nominal contracts. It is costly to renegotiate a contract, so for an individual firm in any given period it is often rational to remain in a sub-optimal price contract. Calvo [1983] presents a highly tractable and widely-used model wherein only a certain fraction of firms are able to adjust prices in each period of time. Little work has been done that would allow economists to predict which firms adjust prices. Future research could establish how firms form their beliefs and how the feedback from the behavior of workers might lead to wage rigidity among a fraction of firms in most countries.

We thank seminar participants at Chapman University and the Workshop on Theoretical and Experimental Macroeconomics. Our paper was improved by conversations with Misha Freer, Steven Gjerstad, Cesar Martinelli, Ryan Oprea, and Arno Riedl. Funding was provided by the National Science Foundation SES 1628911.

\section{References}

J. Abeler, A. Falk, L. Goette, and D. Huffman. Reference points and effort provision. The American Economic Review, 101(2):470-492, 2011. URL http://www.ingentaconnect.com/content/aea/aer/2011/ $00000101 / 00000002 / \operatorname{art} 00002$.

G. A. Akerlof, W. T. Dickens, G. L. Perry, R. J. Gordon, and N. G. Mankiw. The macroeconomics of low inflation. Brookings papers on economic activity, 1996(1):1-76, 1996. URL http://www.jstor.org/ stable/2534646.

T. F. Bewley. Why wages don't fall during a recession. Harvard University Press, 1999.

A. Bracha, U. Gneezy, and G. Loewenstein. Relative pay and labor supply. Journal of labor economics, 33 (2):297-315, 2015. URL http://www. journals .uchicago.edu/doi/abs/10.1086/678494.

J. Brandts and G. Charness. Do labour market conditions affect gift exchange? Some experimental evidence. The Economic Journal, 114(497):684-708, 2004. URL http://onlinelibrary .wiley .com/doi/10.1111/ j.1468-0297.2004.00237.x/full.

J. A. Buchanan. Downward wage rigidity claims and evidence. ICES Working Papers, June 2017.

G. A. Calvo. Staggered prices in a utility-maximizing framework. Journal of monetary Economics, 12(3): 383-398, 1983. URL http://www.sciencedirect.com/science/article/pii/0304393283900600.

C. M. Campbell and K. S. Kamlani. The reasons for wage rigidity: evidence from a survey of firms. The Quarterly Journal of Economics, 112(3):759-789, 1997. URL http://qje.oxfordjournals.org/ content/112/3/759. short.

J. C. Cox and C. A. Deck. On the nature of reciprocal motives. Economic Inquiry, 43(3):623-635, 2005. URL http://onlinelibrary.wiley.com/doi/10.1093/ei/cbi043/full?scrollTo=references.

J. C. Cox, D. Friedman, and S. Gjerstad. A tractable model of reciprocity and fairness. Games and Economic Behavior, 59(1):17-45, Apr. 2007. ISSN 0899-8256. doi: 10.1016/j.geb.2006.05.001. URL http://www.sciencedirect.com/science/article/pii/S0899825606000662.

V. P. Crawford and J. Meng. New york city cab drivers' labor supply revisited: Reference-dependent preferences with rational expectations targets for hours and income. The American Economic Review, 101 (5):1912-1932, 2011. 
M. C. Daly and B. Hobijn. Downward Nominal Wage Rigidities Bend the Phillips Curve. Journal of Money, Credit and Banking, 46(S2):51-93, Oct. 2014. ISSN 1538-4616. doi: 10.1111/jmcb.12152. URL http://onlinelibrary.wiley.com/doi/10.1111/jmcb.12152/abstract.

W. T. Dickens, L. Goette, E. L. Groshen, S. Holden, J. Messina, M. E. Schweitzer, J. Turunen, and M. E. Ward. How Wages Change: Micro Evidence from the International Wage Flexibility Project. The Journal of Economic Perspectives, 21(2):195-214, Apr. 2007.

P. Doerrenberg, D. Duncan, and M. Löffler. Asymmetric labor-supply responses to wage-rate changesevidence from a field experiment. 2016.

E. Fehr and L. Goette. Do workers work more if wages are high? Evidence from a randomized field experiment. The American Economic Review, 97(1):298-317, 2007.

E. Fehr, G. Kirchsteiger, and A. Riedl. Does Fairness Prevent Market Clearing? An Experimental Investigation. The Quarterly Journal of Economics, 108(2):437-459, 1993. ISSN 0033-5533. doi: 10.2307/2118338. URL http://www.jstor.org/stable/2118338.

E. Fehr, O. Hart, and C. A. Zehndera. Contracts as reference pointsexperimental evidence. The American Economic Review, 101(2):493-525, 2011.

U. Fischbacher. z-Tree: Zurich toolbox for ready-made economic experiments. Experimental economics, 10 (2):171-178, 2007. URL http://link.springer.com/article/10.1007/s10683-006-9159-4.

M. Friedman. The role of monetary policy. American Economic Review, 58(1), 1968. URL http://dl4a. org/uploads/pdf/58.1.1-17.pdf.

S. Gachter and C. Thoni. Social comparison and performance: Experimental evidence on the fair wageeffort hypothesis. Journal of Economic Behavior \& Organization, 76(3):531-543, Dec. 2010. ISSN 01672681. doi: 10.1016/j.jebo.2010.08.008. URL http://www.sciencedirect.com/science/article/pii/ S0167268110001538.

R. L. Hannan, J. H. Kagel, and D. V. Moser. Partial gift exchange in an experimental labor market: Impact of subject population differences, productivity differences, and effort requests on behavior. Journal of Labor Economics, 20(4):923-951, 2002. URL http://www. journals .uchicago.edu/doi/abs/10.1086/342894.

D. Kahneman. Thinking, fast and slow. Macmillan, 2011. URL https://books.google.com/books?

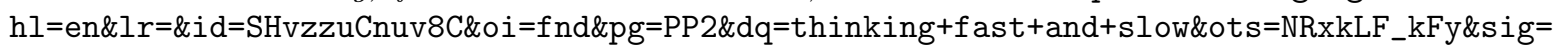
vAAXUmwGETApsZLPvzNI4Uc81kQ.

C. Kendall and R. Oprea. Are biased beliefs fit to survive? an experimental test of the market selection hypothesis. 2016.

B. Köszegi and M. Rabin. A model of reference-dependent preferences. The Quarterly Journal of Economics, 121(4):1133-1165, 2006.

S. Kube, M. A. Marchal, and C. Puppe. Do wage cuts damage work morale? Evidence from a natural field experiment. Journal of the European Economic Association, 11(4):853-870, 2013. URL http:// onlinelibrary.wiley.com/doi/10.1111/jeea.12022/full.

C. N. Noussair, G. Richter, and J.-R. Tyran. Money illusion and nominal inertia in experimental asset markets. Journal of Behavioral Finance, 13(1):27-37, 2012. URL http://www.tandfonline.com/doi/ abs/10.1080/15427560.2012.654546.

S. Schmitt-Grohé and M. Uribe. Downward nominal wage rigidity, currency pegs, and involuntary unemployment. Journal of Political Economy, 124(5):1466-1514, 2016.

J. B. Taylor. Aggregate dynamics and staggered contracts. Journal of political economy, 88(1):1-23, 1980. URL http://www.journals.uchicago.edu/doi/abs/10.1086/260845. 
Table A1: Effort of Workers Round 4-5

\begin{tabular}{|c|c|c|c|}
\hline & \multicolumn{3}{|c|}{ Tobit: effort } \\
\hline & $(1)$ & $(2)$ & $(3)$ \\
\hline Real Wage & & $\begin{array}{c}0.117^{* * *} \\
(0.019)\end{array}$ & \\
\hline Log(Real Wage) & & & $\begin{array}{c}0.197^{* * *} \\
(0.037)\end{array}$ \\
\hline Real Cut, Control & $\begin{array}{c}-0.293^{* *} \\
(0.124)\end{array}$ & $\begin{array}{l}-0.122 \\
(0.074)\end{array}$ & $\begin{array}{c}-0.198^{* * *} \\
(0.073)\end{array}$ \\
\hline R. Cut, Recession & $\begin{array}{c}-0.298^{* * *} \\
(0.107)\end{array}$ & $\begin{array}{c}-0.173^{* *} \\
(0.069)\end{array}$ & $\begin{array}{c}-0.217^{* * *} \\
(0.070)\end{array}$ \\
\hline R. Cut, Inflation & $\begin{array}{c}-0.193^{*} \\
(0.108)\end{array}$ & $\begin{array}{l}-0.050 \\
(0.070)\end{array}$ & $\begin{array}{c}-0.114^{*} \\
(0.069)\end{array}$ \\
\hline Round 5 & $\begin{array}{c}0.030 \\
(0.066)\end{array}$ & $\begin{array}{l}-0.020 \\
(0.032)\end{array}$ & $\begin{array}{l}-0.005 \\
(0.033)\end{array}$ \\
\hline Constant & $\begin{array}{c}0.349^{* * *} \\
(0.038)\end{array}$ & $\begin{array}{l}-0.055 \\
(0.122)\end{array}$ & $\begin{array}{c}0.131 \\
(0.113)\end{array}$ \\
\hline Subject F.E. & No & Yes & Yes \\
\hline Observations & 288 & 288 & 288 \\
\hline Log Likelihood & -207 & 70 & 65 \\
\hline
\end{tabular}

Notes: The table reports results of a tobit regression. The real wage cut dummy variables are equal to 1 if the worker experience a wage cut after round 4 , and 0 otherwise. Standard errors are in parentheses. ${ }^{*} \mathrm{p}<0.1 ;{ }^{* *} \mathrm{p}<0.05 ;{ }^{* * *} \mathrm{p}<0.01$

Table A2: Wage Cuts among Full Sample

\begin{tabular}{rccc}
\hline & Control & Recession & Inflation \\
\hline Average Magnitude of Nominal Wage Cuts & -187 & -142 & -162 \\
\hline Number (\%) of Nominal Wage Cuts & $20(42 \%)$ & $27(56 \%)$ & $19(40 \%)$ \\
\hline Average Magnitude of Real Wage Cuts & -1.43 & -1.09 & -1.09 \\
\hline Number (\%) of Real Wage Cuts & $20(42 \%)$ & $27(56 \%)$ & $25(52 \%)$ \\
\hline Number of Workers & 48 & 48 & 48 \\
\hline
\end{tabular}


Table A3: Profit of Firms in Round 5

\begin{tabular}{|c|c|c|c|c|}
\hline Full Sample & $\mathrm{n}$ & Mean & t-stat. & p-val. \\
\hline No Nominal Wage Cut in Round 5 & 78 & $\$ 2.45$ & \multirow[t]{2}{*}{2.18} & \multirow[t]{2}{*}{0.03} \\
\hline Nominal Wage Cut in Round 5 & 66 & $\$ 1.87$ & & \\
\hline \multicolumn{5}{|l|}{ Cooperating Pairs } \\
\hline No Nominal Wage Cut in Round 5 & 64 & $\$ 2.79$ & \multirow[t]{2}{*}{2.19} & \multirow[t]{2}{*}{0.03} \\
\hline Nominal Wage Cut in Round 5 & 53 & $\$ 2.16$ & & \\
\hline
\end{tabular}

Table A4: Effect of Nominal Wage Cut on Employer Profits

\begin{tabular}{lcc}
\hline \hline & & Firm Profit in Round 5 \\
& $(1)$ & $(2)$ \\
\hline Nominal Cut & $-0.578^{*}$ & $-0.544^{* *}$ \\
& $(0.298)$ & $(0.272)$ \\
& & -0.395 \\
Recession & -0.304 & $(0.330)$ \\
& $(0.350)$ & -0.242 \\
Inflation & 0.025 & $(0.328)$ \\
& $(0.361)$ & $2.646^{* * *}$ \\
Constant & $2.861^{* * *}$ & $(0.258)$ \\
& $(0.274)$ & 144 \\
\hline Observations & 117 & 0.042 \\
R-squared & 0.048 &
\end{tabular}

Notes: The table reports results of an OLS regression. The nominal wage cut dummy variables are equal to 1 if the employer imposed a wage cut after round 4, and 0 otherwise. Model (1) shows data for Cooperating Pairs and (2) shows the full sample. Standard errors are in parentheses. ${ }^{*} \mathrm{p}<0.1 ;{ }^{* *} \mathrm{p}<0.05 ;{ }^{* * *} \mathrm{p}<0.01$ 
Table A5: Actual and Predicted Parameters of the Effort Function, Full Sample Actual Effort, Rounds 4-5 Predictions by Employers for Effort in Round 5 and Actual Effort in Round 4

\begin{tabular}{lcc}
\hline$\beta$ & $0.253^{* * *}$ & $0.237^{* * *}$ \\
& $(0.035)$ & $(0.030)$ \\
$\alpha^{\text {Round } 4}$ & $0.627^{* * *}$ & $0.640^{* * *}$ \\
& $(0.032)$ & $(0.027)$ \\
$\alpha^{\text {Round } 5}$ & $0.599^{* * *}$ & $0.634^{* * *}$ \\
& $(0.035)$ & $(0.031)$ \\
$\lambda^{\text {Nom.Cut }, \text { NoInfl. }}$ & $0.114^{* *}$ & 0.423 \\
& $(0.080)$ & $(0.059)$ \\
$\lambda^{\text {Nom.Cut }, \text { Infl. }}$ & 0.082 & -0.080 \\
& $(0.137)$ & $(0.075)$ \\
\hline Observations & 288 & 288 \\
\hline \hline
\end{tabular}

Notes: The table reports results of a nonlinear regression. The nominal wage cut dummy variables are equal to 1 if the worker experience a wage cut after round 4 , and 0 otherwise. Standard errors are in parentheses. ${ }^{*} \mathrm{p}<0.1 ;{ }^{* *} \mathrm{p}<0.05 ;{ }^{* * *} \mathrm{p}<0.01$

Table A6:

\begin{tabular}{lcc}
\hline \hline & \multicolumn{2}{c}{ Logit: Nominal Wage Cut Probability } \\
& $(1)$ & $(2)$ \\
\hline Loss Tolerance & 0.161 & 0.177 \\
& $(0.105)$ & $(0.109)$ \\
& & \\
Recession & 0.655 & 0.645 \\
& $(0.419)$ & $(0.420)$ \\
Inflation & -0.064 & -0.096 \\
& $(0.420)$ & $(0.424)$ \\
Male & & -0.198 \\
& & $(0.360)$ \\
Constant & $-0.737^{*}$ & -0.669 \\
& $(0.395)$ & $(0.413)$ \\
\hline Observations & 144 & 144 \\
Log Likelihood & -96.511 & -96.359 \\
\hline \hline Note: & & ${ }^{*} \mathrm{p}<0.1 ;{ }^{* *} \mathrm{p}<0.05 ;{ }^{* * *} \mathrm{p}<0.01$ \\
\end{tabular}


Table A7: Beliefs of Loss Averse and Loss Tolerant Employers, Full Sample

\begin{tabular}{lcc}
\hline & Predictions by Loss Averse Firms & Predictions Loss Tolerant Firms \\
\hline$\beta$ & $0.215^{* * *}$ & $0.256^{* * *}$ \\
& $(0.051)$ & $(0.037)$ \\
$\alpha^{\text {Round } 4}$ & $0.651^{* * *}$ & $0.629^{* * *}$ \\
& $(0.048)$ & $(0.033)$ \\
$\alpha^{\text {Round5 }}$ & $0.627^{* * *}$ & $0.604^{* * *}$ \\
& $(0.055)$ & $(0.037)$ \\
$\lambda^{\text {Nom.Cut }, \text { NoInfl. }}$ & 0.210 & -0.022 \\
& $(0.164)$ & $(0.061)$ \\
$\lambda^{\text {Nom.Cut,Infl. }}$ & -0.106 & -0.030 \\
& $(0.102)$ & $(0.122)$ \\
\hline Observations & 108 & 180 \\
\hline \hline
\end{tabular}

Notes: The table reports results of a nonlinear regression. The nominal wage cut dummy variables are equal to 1 if the worker experience a wage cut after round 4, and 0 otherwise. Loss averse firms are those that declined all lotteries or only the first choice (50\% gain $\$ 7$ or $50 \%$ lose $\$ 3$ ). Standard errors are in parentheses. ${ }^{*} \mathrm{p}<0.1 ;{ }^{* *} \mathrm{p}<0.05 ;{ }^{* * *} \mathrm{p}<0.01$

Table A8: Instances of Wage Cuts by Loss Averse Firms, Full Sample

\begin{tabular}{lcc}
\hline & $\begin{array}{c}\text { Employers who Made a } \\
\text { Nominal Wage Cut }\end{array}$ & $\begin{array}{c}\text { Employers who Did Not Make a } \\
\text { Nominal Wage Cut }\end{array}$ \\
\hline Loss Averse Employers & 20 & 34 \\
\hline Loss Tolerant Employers & 44 & 46 \\
\hline
\end{tabular}




\section{B Closed Form Estimates}

\section{B.1 Best-Response Function for a Worker}

This is the derivation of the utility maximizing effort choice by a worker who reciprocates high effort for high wages if $\alpha>0$. Recall the utility function:

$$
U_{t}=w_{t}-c\left(e_{t}\right)+\frac{\alpha}{1+\lambda_{t}} * w_{t}^{\beta} * e_{t}
$$

Obtain the first order condition by setting the derivative $\delta U / \delta e=0$.

$$
w_{t}=1.2 e_{t}^{.5}
$$

Simply solve for effort to obtain the best-response to the wage.

\section{B.2 Optimal Wage for a Profit-Maximizing Employer}

This is the derivation of the optimal wage without loss aversion, assuming an interior solution.

$$
\pi=(R-w) * e
$$

First, substitute effort with the best response function of the worker.

$$
\pi=(R-w) * \frac{\alpha^{2}}{1.44} * w^{2}
$$

We arrive at a first order condition by taking the derivative.

$$
\frac{\delta \pi}{\delta w}=(R-w)\left[2 \beta w^{2 \beta-1}\right]-w^{2 \beta}=0
$$

Rearranging, we simplify to $R-w=\frac{w}{2 \beta}$.

$$
w^{*}=\frac{\beta R}{\beta+1 / 2}
$$

\section{B.3 Derive Threshold level of Loss Aversion for Wage Rigidity to be Optimal Wage-Setting Strategy}

The profit-maximizing condition is $\left(R_{1}-w_{0}\right) \hat{e}\left(w_{0}, \lambda_{I}\right)>\left(R_{1}-w_{1}\right) \hat{e}\left(w_{1}, \lambda_{I}\right)$.

The threshold value is a function of the specific parameters, so the first step is to insert the parameters we use in our experiment: $R_{0}=1150 ; R_{1}=1035 ; \alpha=0.3 ; \beta=0.2$.

Next, we substitute the effort response, $\hat{e}\left(w_{1}, \lambda_{I}\right)=\left(\frac{\alpha}{1.2\left(1+\lambda_{I}\right)}\right)^{2} * w_{1}^{2}$. Rearrange to solve and find $\underline{\lambda}>1.002$.

\section{Text of the Instructions}

Welcome. You have the opportunity to earn cash at the end of this experiment based on the decisions made by you and others. At the end of the experiment and after a questionnaire, you will be paid the total amount you have earned in the experiment plus $\$ 5$ for arriving on time today.

Out of several participants, half of you are randomly selected to be employers and half of you are employees. No one will know your identity or the actions you take during this experiment.

At any time during the instructions, raise your hand and the experimenter will answer questions. Please turn off all electronic devices. Talking or communication is not allowed during the experiment. 
To calculate how much money you can earn, you will use addition and multiplication. The first computer screen is to practice calculation and opening the calculator tool. Click Begin on the screen to start the math practice. Click on the calculator icon to open the calculator tool.

Add the following numbers together. $12.34+56$

Multiply these two numbers. $\quad 45 \times 9.01$

Type your answers into the boxes on the screen. Click Submit Calculations to continue. This is a timeline for the experiment. There are 7 rounds. In every round, there are 3 steps. Some questions will be asked after Round 5 and after Round 7.

\begin{tabular}{|cl|l|}
\hline Stage 0 & Round 1 & $\begin{array}{l}\text { Step 1 } \\
\text { Step 2 } \\
\text { Step 3 }\end{array}$ \\
\hline Stage 1 & $\begin{array}{l}\text { Round 2 } \\
\text { Round 3 } \\
\text { Round 4 }\end{array}$ & Steps... \\
\hline & Round 5 & Questions \\
\hline Stage 2 & Round 6 & \\
& Round 7 & \\
\hline Questionnaire & & \\
\hline
\end{tabular}

If you are an employee you will be matched with one of the employers for all rounds. Each repeated round will consist of the following steps, although some rounds do not include step 1.

\section{Step 1:}

An employer sets a salary that they will pay (this will not happen in Round 3,4,6, or 7). The salary number is in Experiment Currency Units (ECUs), the tickets that you earn during the experiment. The employer cannot set a wage that is so high that the employer will lose money or that is so low that the employee will lose money.

The employer sets a salary or wage in Round 1 . They can change that wage or keep the same wage for Round 2. The wage will stay the same for rounds 2, 3 and 4. Employers may change the wage between Round 4 and Round 5, or they may keep the wage the same. The wage in Round 5, 6, and 7 will be the same.

\begin{tabular}{|cl|l|}
\hline Stage 0 at wage $_{0}$ & Round 1 & $\begin{array}{l}\text { Step 1: Set first wage level for Round 1 } \\
\text { Step 2: Set first effort level } \\
\text { Step 3: Review payments }\end{array}$ \\
\hline Stage 1 at wage $_{1}$ & $\begin{array}{l}\text { Round 2 } \\
\text { Round 3 } \\
\text { Round 4 }\end{array}$ & Set a wage for Rounds 2-4 \\
\hline Stage 2 at wage 2 & $\begin{array}{l}\text { Round 5 } \\
\text { Round 6 } \\
\text { Round 7 }\end{array}$ & Questions \\
\hline Questionnaire & & \\
\hline
\end{tabular}

\section{Step 2:}

The employee observes the wage and chooses his or her effort level. The possible effort choices are shown in this table:

\begin{tabular}{|l|l|l|l|l|l|l|l|l|l|l|l|l|l|l|l|l|l|l|l|}
\hline .05 & 0.1 & .15 & 0.2 & .25 & 0.3 & .35 & 0.4 & .45 & 0.5 & .55 & 0.6 & .65 & 0.7 & .75 & 0.8 & .85 & 0.9 & .95 & 1 \\
\hline
\end{tabular}

Participants review the results from the round. Results are displayed in Experiment Currency Units (ECUs) they earned during the round. ECUs will be exchanged for dollars in cash at the end according to an exchange rate. 
C. TEXT OF THE INSTRUCTIONS

How to Earn Money

An employee earns a wage from the employer. The employee pays the cost of the effort level that he or she chooses. Practice reading the cost of effort table (split into two tables). .

\begin{tabular}{|}
\begin{tabular}{|c|c|c|c|c|c|c|c|c|c|c|}
\hline Effort & 0.05 & 0.1 & 0.15 & 0.2 & 0.25 & 0.3 & 0.35 & 0.4 & 0.45 & 0.5 \\
\hline Cost & $\$ 0.01$ & $\$ 0.03$ & $\$ 0.05$ & $\$ 0.07$ & $\$ 0.10$ & $\$ 0.13$ & $\$ 0.17$ & $\$ 0.2$ & $\$ 0.24$ & $\$ 0.28$ \\
\hline Effort & 0.55 & 0.6 & 0.65 & 0.7 & 0.75 & 0.8 & 0.85 & 0.9 & 0.95 & 1 \\
\hline Cost & $\$ 0.33$ & $\$ 0.37$ & $\$ 0.42$ & $\$ 0.47$ & $\$ 0.52$ & $\$ 0.57$ & $\$ 0.63$ & $\$ 0.68$ & $\$ 0.74$ & $\$ 0.80$ \\
\hline
\end{tabular}
\end{tabular}

Every effort level has a cost paid by the worker. For example, the cost of the effort level 0.5 is 28 cents or $\$ 0.28$, located directly under 0.5 in the table. A worker has to pay 80 cents for an effort level of 1 .

Note that a worker earns a wage in ECUs and pays the cost of effort in dollars. The workers payment for a round is the value of their ECU wage minus the cost of effort they pay.

On the next computer practice screen, enter the effort level that costs $\$ 0.24$ Enter the effort level that costs $\$ 0.57$

Click the Submit Effort Answers button.

The amount that an employer earns in one round depends on the wage and the effort of the employee they are matched with.

This is how the employer is compensated: The employer subtracts the wage from 1150 and then multiplies that number by the effort level of the employee.

In one round the employer earns

$$
(1150-\text { wage }) \times \text { effort level }
$$

To do a practice calculation on the next practice screen, first type in a wage. Second, select an effort level. Click the Submit Effort Level button.

Make your practice calculation by subtracting the wage you entered from 1150 (use the calculator if you need it). Then, multiply that number by the effort level you selected.

If the answer you calculate has a number after the decimal point, round your answer. For example, 400.5 rounds up to 401 and 300.2 rounds down to 300 .

Your choices cannot cause the example worker to lose money. If you make a choice that would lead to losing money, a pop up message will notify you. Note that effort costs money.

Enter the profit and then click Submit Profit Calculation. When you enter the correct calculation, you can advance to the next practice screen. Please raise your hand if you have a question and the experimenter will help you.

At the end of the experiment, you will be paid for all 7 rounds. The exchange rate is 1 dollar for every 130 ECUs.

It is possible that there will be a one-time change in the exchange rate or other numbers for the profit calculation between Stage 1 and Stage 2. If that happens, you will be notified.

Do not talk to other participants during the experiment. If you have a question, ask the experimenter.

Review

During a round, employers set a wage and then employees set an effort level.

Employees earn

$$
\text { wage - cost of effort }
$$

Employers earn

$$
(1150-\text { wage }) \times \text { effort level of employee }
$$




\section{TEXT OF THE INSTRUCTIONS}

During the experiment, participants earn experimental currency units (ECU) that are exchanged for dollars at the end based on the exchange rate.

Some questions will be asked after round 5 and after round 7 .

The next screen informs you of your role in the experiment.

Click OK. Next, you will begin Round 1 and employers will set the first wage.

Any further instruction you will need will be on the computer screen. Keep this instruction sheet at your desk for reference. 